\title{
Desenvolvimento de modelo conceitual de telha ecológica a partir de resíduos de PET e gesso da construção
}

\section{(Development of a conceptual model of an ecologic tile using building plasters waste)}

\author{
S. Teske, P. F. A. Gonçalves, A. Nagalli \\ Departamento Acadêmico de Construção Civil, Universidade Tecnológica Federal Do Paraná, Campus \\ Curitiba, Sede Ecoville, R. Deputado Heitor de Alencar Furtado 4900, Curitiba, PR 81280-340 \\ nagalli@utfpr.edu.br
}

\begin{abstract}
Resumo
Este trabalho apresenta o gesso na construção civil, suas aplicações, características e o desperdício associado. É exposta a legislação brasileira pertinente ao gerenciamento dos resíduos sólidos na construção, e mais especificamente as resoluções CONAMA 307/02 e 431/11, em que o resíduo de gesso passou a ter uma reclassificação quanto a sua destinação. Assim, esse passou a ser considerado um material passível de reutilização e reciclagem. Dessa forma, o objetivo do trabalho foi investigar a viabilidade técnica de aproveitamento de resíduos de gesso como matéria-prima para materiais de construção, no caso, pela incorporação deste em telhas. Assim, é feita uma descrição dos tipos de telhas, suas características e métodos de fabricação, como também a exposição de dois tipos de telhas recicladas. É descrito também o albedo, associado com o benefício de telhados brancos na redução da temperatura dentro das edificações nos dias de maior calor. Foi feita uma lista com as formas e cobrimentos possíveis para a adaptação do gesso na telha, e a partir de características favoráveis às telhas foi escolhido o modelo a ser detalhado, a partir de uma matriz avaliativa. O modelo escolhido foi o Colonial Gigante, com capa polimérica feita de resíduo de PET (politereftaleno de etileno) envolvendo o resíduo de gesso. Um modelo 3D foi desenvolvido, e a telha foi nomeada de Telha GePET. Foram definidas em laboratório a umidade e a massa específica aparente e unitária do resíduo de gesso. Diversas características da telha foram descritas, como suas dimensões, massa, fonte de matéria-prima, produção, instalação no telhado, manutenção e durabilidade, o descarte após sua vida útil, o albedo, o isolamento térmico e o valor da telha. Concluiu-se que é possível a fabricação de uma telha com resíduos de gesso, juntamente com o resíduo de PET, tornando-a um produto mais sustentável e 100\% reciclável.
\end{abstract}

Palavras-chave: reciclagem, gesso, PET, telha sustentável, albedo.

\begin{abstract}
First of all this work presents plaster on civil construction, its application, features and its waste. In sequence is shown some legislation regarding solid waste management in building industries and specifically on the CONAMA resolutions 307/02 and $431 / 11$ in which the residue of plaster has been reclassified about its destination. With the reclassification it is considered a feasible material to reuse and recycle. Then are mentioned some case studies that demonstrate the possibility of the reuse of plaster. The work objective was to investigate the technical feasibility of plaster waste as a raw material for building materials, in this case to be incorporated on a tile. So, a description is given of the types of tiles, its characteristics and manufacturing methods, as well as two types of recycled tiles. It is also described the albedo, associated with the benefit of white roofs in the temperature reduction of the buildings in the hottest days. A list of possible forms and coverings to adapt the plaster on the tile were made, and from the propitious characteristics of tiles an evaluative matrix was made, so a tile to be detailed was chosen from it. The chosen model was the Giant Colonial, with a polymeric cover made of PET (polyethylene terephthalate) waste involving the plaster waste. A $3 D$ model was developed and the tile was called GePET tile. Moisture, density and true density of the gypsum residue was defined in the laboratory. Several features of the tile were described as their size, weight, the source of raw material, production, roof installation, maintenance and durability, discard after their life cycle, albedo, thermal insulation and the cost of the tile. It was concluded that manufacturing a tile with plaster waste is possible, associated with PET waste, making product sustainable and $100 \%$.
\end{abstract}

Keywords: recycling, plaster, PET, sustainable tile, albedo.

\section{INTRODUÇÃO}

O gesso no Brasil é produzido a partir de matériasprimas naturais, e seu processo produtivo inclui: extração do minério, britagem, moagem grossa, estocagem com homogeneização, secagem, calcinação, moagem fina, ensilagem e ensacamento. A calcinação é um processo industrial de aquecimento em um ou dois fornos cujo produto é o hemidrato puro ou contendo também gipsita ou anidrita, sendo que, a composição do produto dependerá de sua aplicação [1]. As impurezas presentes como $\mathrm{SiO}_{2}, \mathrm{Al}_{2} \mathrm{O}_{3}$, $\mathrm{FeO}, \mathrm{CaCO}_{3}, \mathrm{Mg}$ não passam de $6 \%$ [2]. As proporções 
dos elementos, a eventual presença de inertes e sua finura são determinantes para a caracterização das propriedades do gesso no estado fresco ou endurecido, incluindo propriedades mecânicas, físicas, tempo de pega e outros [1]. O gesso é o aglomerante menos utilizado no Brasil, porém este apresenta características e propriedades importantes como a plasticidade da pasta fresca e a lisura da superfície endurecida, como também o endurecimento rápido [3].

Considera-se desperdício não só o rejeito do canteiro de obras, mas toda e qualquer perda durante o processo [4]. As perdas podem acontecer em três diferentes fases: a concepção, a execução e a utilização [5]. Outro fator agravante é a falta de tecnologia do setor de edificações, tanto no Brasil como no mundo, sendo bem evidenciado o desperdício de materiais e mão de obra [6]. Especificamente na utilização do gesso na construção a realidade não é diferente.

O processo de separação do entulho de peças prémoldadas e de gesso acartonado são facilitadas por terem maior tamanho e por ficarem separados de outros materiais construtivos, diferentemente da pasta de gesso que por conta de sua aderência a outros materiais, torna inviável a separação [7]. O volume de resíduos gerados depende da modulação da obra e da qualidade das peças, sendo que a Associação Brasileira de Gesso (Abragesso) estima um percentual de 5\% no Brasil, porém em pesquisas feitas com instaladores o valor estimado foi de $12 \%[1,8]$.

Ao notar a necessidade de controlar e implementar diretrizes para "a efetiva redução dos impactos ambientais gerados pelos resíduos oriundos da construção civil" [9] o Conselho Nacional do Meio Ambiente (Conama) definiu em 2002, na resolução 307/02, critérios e responsabilidades quanto à destinação dos resíduos que contribuem para a perda da qualidade ambiental ao serem descartados de maneira inadequada. O Conama apresentou três outras resoluções contendo alterações, sendo que uma mudança significativa que ocorreu na gestão do resíduo de gesso foi na resolução 431/11 [10].

Com o intuito de obter uma destinação adequada para o resíduo de gesso, diversos estudos estão sendo feitos, desde a reutilização do gesso após moagem e calcinação [11], até a utilização do gesso com outras finalidades como, por exemplo, o seu uso como fertilizantes na agricultura $[12,13]$. Ao analisar o resíduo de gesso, verificou-se que a sua cor branca poderia ser favorável à fabricação de telhas brancas, fator este positivo em sua comercialização. O telhado branco possui uma propriedade de refletância da energia solar, reduzindo os efeitos e absorção, transferência e acumulação de calor. Sendo assim é possível que a temperatura interna das edificações seja menor, em relação a outros tipos de telhados. A diminuição da temperatura interna é favorável nos períodos de calor, e também em grandes cidades influenciadas pelo fenômeno das ilhas de calor. Porém, o gesso é um material higroscópico que absorve ou libera a umidade que está contida no ambiente [14]. Neste sentido, há a necessidade de materiais impermeabilizantes que impeçam o contato da água com o gesso da telha. Um produto que manteria a propriedade branca, por apresentar essa cor seriam os impermeabilizantes brancos à base de resina acrílica. Eles são impermeáveis, flexíveis, resistem às intempéries, aos raios ultravioleta, ao ozônio e as névoas salinas. Este tipo de impermeabilização é indicado para áreas expostas como: lajes expostas sem trânsito, telhas de fibrocimento e outros [15]. Outra alternativa é o uso de polímeros, reciclados ou não, como camada de proteção para o gesso. É evidente que o rol de produtos não se atém apenas aos mencionados, sendo imprescindível o estudo mais aprofundado dos tipos de materiais que poderiam ser empregados juntamente com o gesso na telha.

As telhas de PET (polímero) são produzidas a partir da extrusão e injeção do material polimérico com carbonato de cálcio, sendo incluídos também aditivos de proteção antiUV. As telhas feitas de resíduos de PET apresentam diversas vantagens, entre elas: não apresentam alta porosidade evitando assim o acúmulo de umidade e mofo, e por isso não há necessidade de limpeza constante dos telhados, maior durabilidade, formas diferenciadas, e o diferencial ambiental. Porém, uma grande desvantagem desse tipo de telha é que o seu preço é bem mais elevado que a telha convencional de barro, mas associado ao fato de que ela é muito mais leve e exige uma estrutura de telhado menos robusta, a cobertura completa acaba sendo mais econômica [16].

Dessa forma, o objetivo geral deste trabalho foi desenvolver um modelo conceitual de telha cujas matériasprimas principais utilizadas fossem resíduos de PET e de gesso proveniente de obras civis. Sendo assim, a produção da telha de gesso, além de estabelecer uma destinação para os resíduos de gesso, traria também o benefício da cor branca na cobertura, acarretando em uma diminuição da temperatura interna das edificações, especialmente nos dias de maior incidência de energia solar.

\section{MATERIAIS E MÉTODOS}

Para se alcançar o modelo final da telha, suas características e potencialidades foram adotados os seguintes passos, apresentados em forma de fluxograma (Fig. 1).

\section{Definição da telha}

Para a definição do melhor formato e impermeabilização da telha de gesso, assim como, a maneira em que o resíduo de gesso seria incorporado à telha, foram investigados, avaliados e listados os modelos de telhas existentes no mercado. Em seguida, diante dos muitos tipos de telhas, foram escolhidos dez modelos diferentes para serem inseridos em uma matriz avaliativa, que estabeleceu critérios de escolha para a telha-modelo. Nesta avaliação, atribuíramse valores para cada um dos 10 critérios escolhidos. Os critérios abrangeram aspectos geométricos, estruturais e de desempenho das telhas. Assim, para cada critério e tipo de telha foi estabelecido valor de 1 a 5 , sendo 1 o pior caso e 5 o melhor caso para os fatores: ecológico, durabilidade, peso, método construtivo, rendimento, mercado, manutenção e 


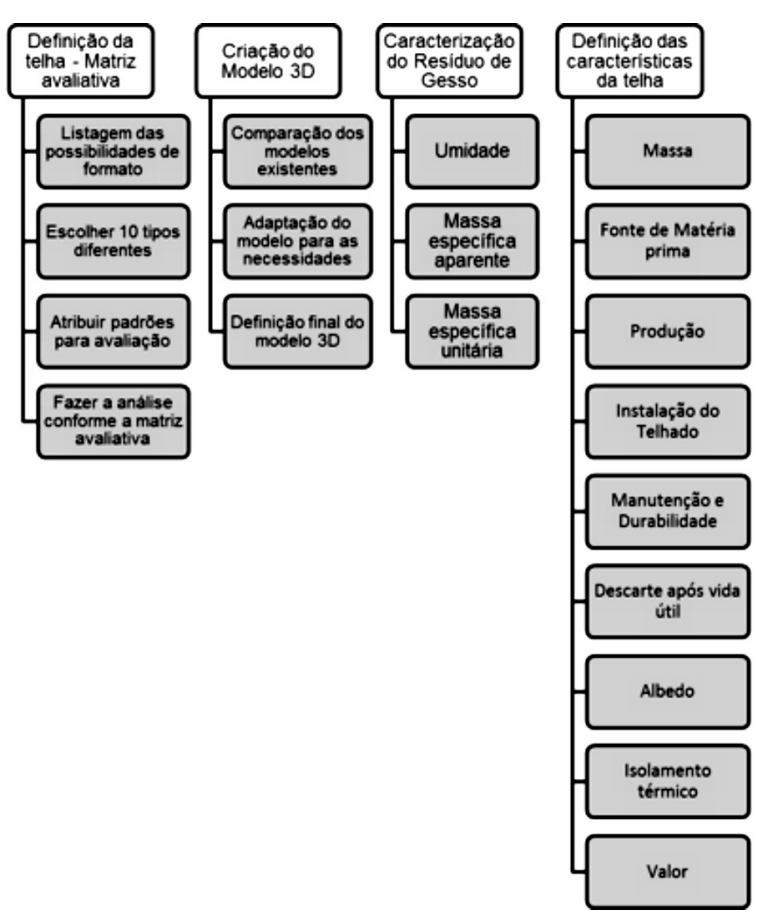

Figura 1: Fluxograma dos procedimentos realizados para o desenvolvimento do trabalho.

[Figure 1: Flowchart of procedures performed for the development of the work].

descarte. Foram considerados também os fatores referentes às incertezas de mercado que avaliam como um produto responderá comercialmente. Em uma escala de valores de 0,1 a 0,9 , do indesejável ao desejável respectivamente, se estabeleceram as probabilidades de sucesso técnico, comercial e econômico. Depois da avaliação de cada um dos componentes, cada valor foi multiplicado entre si, de modo que o resultado da multiplicação (subtotal) ampliasse ao espectro de visualização do desempenho no conjunto de critérios analisados. Então o valor único de cada telha gerado pôde ser comparado entre si, e enfim ser escolhido o conjunto mais favorável à telha de resíduo de gesso e PET. Após esta definição, partiu-se para o projeto da telha em CAD, estabelecendo-se suas dimensões e volumetria. Para isso adaptaram-se os padrões de medidas da empresa Maristela e da NBR 15130/09 [17]. O modelo 3D foi gerado no programa Autocad, da Autodesk, donde se extraíram seus parâmetros geométricos (áreas superficiais, volumes, etc.). Foi também desenhado um metro quadrado de telhado para verificar quantas peças de telhas são necessárias por metro quadrado, pois esta medida é muito usada para o dimensionamento de telhados.

Determinação da umidade, massa especifica aparente e da massa específica unitária dos resíduos de gesso e pet

O resíduo de gesso utilizado nos ensaios foi obtido em uma obra em Curitiba entre 19/07/2013 e 26/07/2013. Esse era composto por pedaços de placas de gesso acartonado, gesso desempenado, pedaços de sancas e placas de forro de gesso. Foi realizada uma separação manual dos materiais indevidos, isto é, resíduos não constituídos por gesso em função de uma não segregação cuidadosa no canteiro de obras. As normas utilizadas para a realização dos ensaios foram a ABNT NBR NM 45/2006 [18] e a ABNT NBR NM $52 / 2009$ [19].

Inicialmente, o material coletado foi disposto em um recipiente metálico e quantificou-se sua massa úmida. $\mathrm{O}$ resíduo foi colocado em estufa à temperatura de $105^{\circ} \mathrm{C} \pm$ $5{ }^{\circ} \mathrm{C}$ durante uma semana, por motivo de disponibilidade para se realizar os ensaios. Após este período, o material foi retirado da estufa, tendo sido pesado mais uma vez para a determinação da umidade do gesso coletado. O resíduo de gesso foi moído no moinho de abrasão "Los Angeles" durante 250 voltas, resultando em uma granulometria mais fina, desejada para a inserção na telha e para a execução do ensaio. Para que resíduo de gesso incorporado não fosse de grandes diâmetros, se estabeleceu um padrão máximo para este diâmetro. O diâmetro máximo escolhido, compatível com a produção da telha, foi o passante pela peneira de 2,38 $\mathrm{mm}$. Então o resíduo foi peneirado e o material passante foi utilizado para a determinação da massa específica aparente e unitária. Para a massa específica aparente, foi primeiramente pesado o recipiente cilíndrico, e lançado na altura do bocal o resíduo moído até que fosse completamente cheio, e então foi arrasado e pesado. Este procedimento de medição do gesso foi realizado em triplicata. O recipiente foi limpo e preenchido com água para determinação do volume do mesmo, considerando-se que a massa específica da água é de $1 \mathrm{~g} / \mathrm{cm}^{3}$. Em seguida foi determinada a massa específica unitária dos resíduos de gesso sendo utilizado um frasco aferido. Assim, foram medidas as massas do frasco aferido vazio e cheio de água. Depois, foi inserida uma quantidade pequena de gesso, e medida a massa, então foi adicionada água ao recipiente, sendo retiradas as bolhas de ar internas, tendo sua massa novamente medida. Desta forma foi possível definir a massa específica unitária do resíduo de gesso. As características do PET reciclado adotadas na concepção da telha foram obtidas da literatura $[16,20]$.

\section{Características da telha}

Uma das importantes características da telha é sua massa. Com o modelo 3D da telha foi possível extrair os volumes, tanto do espaço a ser preenchido com resíduos de gesso quanto da cobertura de PET reciclado de forma sólida. A partir da determinação da massa específica aparente do resíduo de pó de gesso e da massa específica aparente do PET reciclado, foi possível estimar a massa da telha. Para a caracterização do processo produtivo da telha, foram estimados a procedência da matéria-prima, o método construtivo a ser adotado e dados de processos similares, principalmente quanto à reciclagem do PET. Para o gesso, foram adotados processos que retirassem a umidade do gesso, como também permitissem que este fosse de granulometria compatível com o espaço disponível na telha. Para a instalação do telhado foram levadas em 
consideração as recomendações de inclinação da empresa Maristela, produtora também da telha Colonial Gigante, como também de outras empresas especializadas. Para a montagem é necessário o valor da galga média, que deve ser também especificado pelo fabricante. A galga média se refere às medidas das distâncias mínima e máxima de montagem das telhas, e depois de feita a média esse valor pode ser utilizado como padrão de distanciamento das telhas por meio das distâncias das ripas. Para a definição teórica da galga média do modelo, consideraram-se as distâncias máximas e mínimas de encaixe posterior com o superior da peça. Após definidas estas distâncias por meio do modelo 3D, foi feita a média e a galga média foi estabelecida. Este valor foi imprescindível para definir a distância do ripamento na montagem da estrutura do telhado. A manutenção, durabilidade e descarte da telha foram estimados por meio das propriedades e características dos materiais componentes, gesso e PET reciclado, e como são influenciados pelas intempéries separadamente, principalmente no caso da parte externa de PET relativo à manutenção e durabilidade, pois é a parte mais sujeita por estar diretamente exposta. Quanto ao descarte, este foi definido de cada componente separadamente, conforme as recomendações de cada material da atualidade. Também foram considerados o albedo e o isolamento térmico da telha, que foram caracterizados conforme as propriedades dos materiais constituintes, sendo consideradas suas propriedades separadamente. Como parte importante na viabilidade do produto, o custo da telha foi estimado considerando o custo da produção do PET e do gesso separadamente e então somados. Primeiramente foi estabelecido o custo da parte de PET tomando em conta o preço e a massa de uma telha de PET translucida colonial semelhante ao modelo, sendo feita uma proporção de preço com relação à massa da telha. Considerando que dentro do custo da telha já se incluem questões comerciais como divulgação e transporte, foi definido que este seria o valor final apenas somado com os custos para o processamento do gesso. Então foi feito um estudo comparativo do modelo estudado, com a telha plástica existente no mercado e também com a telha colonial gigante cerâmica, através dos custos e massa por metro quadrado. Por fim, foram listadas as diversas vantagens e desvantagens da telha.

\section{RESULTADOS E DISCUSSÃO}

\section{Definição da telha}

Depois de realizada pesquisa com vários produtores de telhas de diversos materiais para verificação de quais são os modelos disponíveis no mercado, foram verificadas dez possibilidades de telhas com formas em que seria possível fazer o aproveitamento de gesso, as quais foram: Colonial, Paulista, Colonial Gigante, Plan, Francesa, Romana, Portuguesa, Alemã (ou de sobreposição), Coppo Veneto, Plana, Ondulada, Trapezoidal e em chapa. Foi considerado também que o resíduo de gesso a ser utilizado, poderia ser incorporado de três formas: recalcinado e moldado conforme o modelo escolhido, prensado ou o resíduo em pó. E para impedir que a água entrasse em contato com o gesso, foram encontradas três formas para garantir a cobertura e impermeabilização do gesso, por meio de: vidro, polímeros, entre eles escolhido o PET reciclado, ou

Tabela I - Matriz avaliativa das características da telha.

[Table I - Evaluative matrix of characteristics tile.]

\begin{tabular}{|c|c|c|c|c|c|c|c|c|c|c|c|}
\hline & FATOR & 1 & 2 & 3 & 4 & 5 & 6 & 7 & 8 & 9 & 10 \\
\hline 1 & \multirow{2}{*}{ Ecológico } & 4 & 2 & 5 & 3 & 5 & 5 & 5 & 5 & 4 & 4 \\
\hline 2 & & 3 & 3 & 3 & 3 & 3 & 3 & 3 & 3 & 2 & 2 \\
\hline 3 & Durabilidade & 4 & 4 & 4 & 4 & 2 & 4 & 2 & 4 & 4 & 4 \\
\hline 4 & \multirow{2}{*}{$\begin{array}{c}\text { Peso } \\
\text { Método } \\
\text { construtivo }\end{array}$} & 3 & 1 & 3 & 4 & 5 & 4 & 4 & 4 & 4 & 4 \\
\hline 5 & & 4 & 3 & 5 & 4 & 3 & 3 & 4 & 4 & 4 & 4 \\
\hline 6 & Rendimento & 5 & 5 & 5 & 3 & 2 & 3 & 5 & 3 & 3 & 3 \\
\hline 7 & Mercado & 3 & 3 & 2 & 3 & 2 & 3 & 2 & 3 & 3 & 4 \\
\hline 8 & Manutenção & 4 & 4 & 4 & 4 & 2 & 4 & 2 & 4 & 4 & 4 \\
\hline \multirow[t]{3}{*}{9} & Descarte & 4 & 4 & 4 & 4 & 3 & 4 & 3 & 4 & 4 & 4 \\
\hline & SUBTOTAL & 138.240 & 17.280 & 144.000 & 82.944 & 10.800 & 103.680 & 28.800 & 138.240 & 73.728 & 98.304 \\
\hline & \multicolumn{11}{|l|}{ INCERTEZA } \\
\hline 10 & Sucesso técnico & 0,8 & 0,6 & 0,6 & 0,8 & 0,7 & 0,7 & 0,7 & 0,7 & 0,7 & 0,7 \\
\hline 11 & $\begin{array}{l}\text { Sucesso } \\
\text { comercial }\end{array}$ & 0,7 & 0,5 & 0,4 & 0,7 & 0,5 & 0,6 & 0,5 & 0,6 & 0,5 & 0,6 \\
\hline \multirow[t]{3}{*}{12} & $\begin{array}{c}\text { Sucesso } \\
\text { econômico }\end{array}$ & 0,7 & 0,5 & 0,6 & 0,7 & 0,7 & 0,7 & 0,7 & 0,7 & 0,6 & 0,6 \\
\hline & SUBTOTAL & 0,392 & 0,15 & 0,144 & 0,392 & 0,245 & 0,294 & 0,245 & 0,294 & 0,21 & 0,252 \\
\hline & TOTAL & 54.190 & 2.592 & 20.736 & 32.514 & 2.646 & 30.482 & 7.056 & 40.643 & 15.483 & 24.773 \\
\hline
\end{tabular}


impermeabilizantes brancos. Um quadro foi montado para juntar quais possibilidades estão de acordo entre si, sendo ao todo 64 possibilidades de telhas diferentes. Diante da variedade encontrada foi necessário selecionar inicialmente 10 para o próximo passo do estudo. As 10 opções iniciais foram escolhidas de forma sensorial, sendo que o objetivo da escolha foi incluir opções que fossem diferentes e que se apresentassem como uma opção mais viável, ao ser analisado teoricamente. A matriz avaliativa possibilitou escolher e ter mais clareza sobre o melhor modelo, tipo de preenchimento e cobertura para o modelo de telha. A Tabela I apresenta os valores dados para cada categoria em relação ao modelo 1 a 10 indicados acima, suas potencialidades de mercado e o resultado final do processamento, pela totalização dos pontos. A subtotalização aconteceu pelo produto entre os indicadores (1 a 9 ou 10 a 12) em cada um dos fatores e incertezas analisados.

O modelo de telha cuja multiplicação dos valores na avaliação resultou em mais pontos foi a adotada para a continuidade do trabalho foi o tipo 1, que possui o formato Colonial Gigante. Está terá uma cobertura de PET reciclado e será incorporado dentro da capa de PET o gesso de forma em pó. Para a determinação exata do formato da telha e o

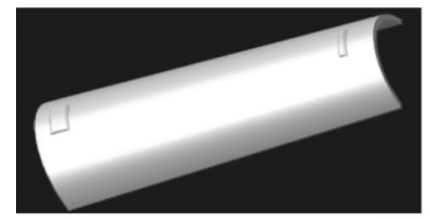

(A)

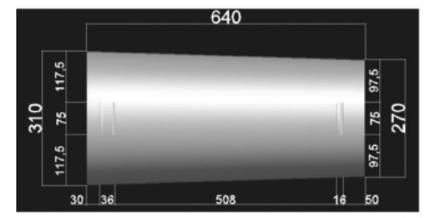

(C)

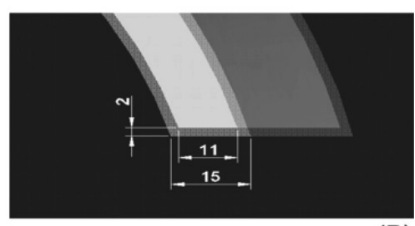

(B)
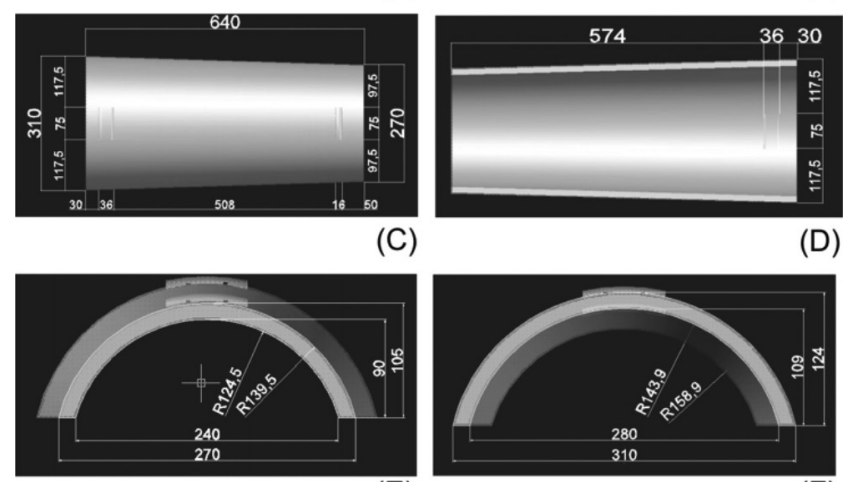

(E)

(F)

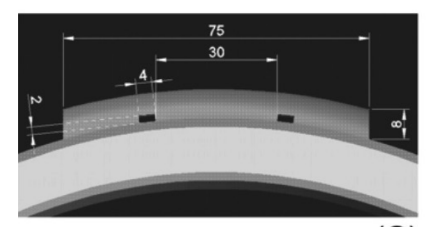

(G)

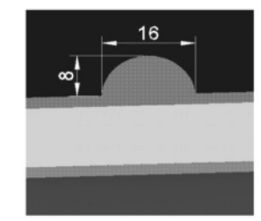

$(\mathrm{H})$

Figura 2: Características dimensionais da telha GePET. Dimensões em mm. (A) Modelo 3D; (B) Detalhe das dimensões de espessura; (C) Dimensões, vista superior; (D) Dimensões vista inferior; (E) Dimensões da lateral de menor raio; (F) Dimensões da lateral de maior raio; $(\mathrm{G})$ Detalhe das dimensões do apoio; $(\mathrm{H})$ Detalhe do corte do apoio de menor dimensão.

[Figure 2: Dimensions (mm) of GePET tile.(A) 3D model; (B) details of thickness; (C) top view; (D) bottom view; (E) low radius side view; (F) high radium side view; $(G)$ support; (H) support cross view.] desenho do modelo 3D tomou-se como base a telha colonial gigante da empresa Maristela que produz telhas deste formato cerâmicas, e da NBR 15130/09 que estabelece padrões e ensaios para peças cerâmicas, incluindo a telha colonial. Para referenciar o modelo escolhido, foi adotado o nome de telha GePET para o modelo, significando a união do gesso e do PET para a produção da telha.

A Fig. 2A apresenta o modelo 3D completo desenvolvido no Autocad. A parte branca que está mais em evidência representa o pó de gesso inserido, e a camada cinza externa representa o cobrimento de PET. A Fig. 2B mostra em detalhe a espessura da camada de PET que será de $2 \mathrm{~mm}$, e a espessura total da lateral da telha que será de $15 \mathrm{~mm}$. A Fig. 2C mostra as dimensões da vista superior da telha GePET, sendo cotadas suas dimensões totais, como também as dimensões dos apoios da peça. Todas as dimensões estão em milímetros. A Fig. 2D mostra as dimensões da parte posterior da telha, mostrando a localização do sulco de encaixe. Nas Figs. 2E e $2 \mathrm{~F}$ são mostradas as dimensões e curvaturas das laterais da telha, sendo que a Fig. 2E mostra a lateral de menor raio e comprimento e a Fig. $2 \mathrm{~F}$ mostra a lateral de maior raio e comprimento. Para encaixe e amarração da telha no ripamento, foram dimensionados apoios e pequenos furos nestes apoios para ser possível a amarração, uma vez que não será possível fazer furos no modelo por possibilitar que o recheio saia, ou entre algum tipo de umidade. A Fig. 2G mostra em detalhe a vista frontal dos apoios, sendo equivalente para os dois tipos. A Fig. $2 \mathrm{H}$ mostram o corte de um dos apoios e suas dimensões, onde há o encaixe das peças.

Determinação da umidade, massa especifica aparente e da massa específica unitária dos resíduos de gesso

Conforme definido em laboratório, a umidade encontrada no resíduo de gesso coletado foi de $14,5 \%$. Os valores das massas obtidas foram: 528,2 g, 3152,0 g e 2771,8 g, sendo a massa do recipiente, a massa do gesso úmido e a massa de gesso seco, respectivamente. A determinação da massa específica aparente do resíduo de gesso é apresentada na Tabela II.

Como a densidade da água é $1 \mathrm{~g} / \mathrm{cm}^{3}$, pode-se definir de forma exata que o volume do recipiente é igual a sua massa $398,9 \mathrm{~cm}^{3}$. Inseridos os valores médios, juntamente com o volume, pode-se definir a massa específica aparente do resíduo de gesso por $0,802 \mathrm{~g} / \mathrm{cm}^{3}$. Nota-se que a variância, desvio padrão e intervalo de confiança (para $\alpha=0,95)$, sinalizam que as medições apresentam boa representatividade. Já na determinação da massa unitária, a massa do frasco tem 72,2 g, e o frasco cheio de água tem 319,1 g. As massas obtidas com o gesso somado com o valor da massa unitária encontram-se na Tabela III.

O valor médio encontrado para a massa específica unitária foi de 2,45 g/ $\mathrm{cm}^{3}$. Da análise das médias, variância, desvio padrão e intervalo de confiança (para $\alpha=0,95$ ) mostrados na Tabela III, tem-se que as medições apresentam representatividade regular. 
Tabela II - Determinação da massa específica aparente do resíduo de gesso.

[Table II - Determination of bulk density of the gypsum waste.]

\begin{tabular}{|c|c|c|c|c|}
\hline $\begin{array}{l}\text { Recipiente } \\
\text { (g) }\end{array}$ & $\begin{array}{c}\text { Recipiente } \\
\text { (g) }\end{array}$ & $\begin{array}{l}\text { Gesso } \\
(\mathrm{g})\end{array}$ & $\underset{\text { (g) }}{\text { Recipiente }}+$ água & $\begin{array}{l}\text { Água } \\
\text { (g) }\end{array}$ \\
\hline \multirow{3}{*}{711,8} & 1036,2 & 324,4 & \multirow{4}{*}{1110,7} & \multirow{4}{*}{398,9} \\
\hline & 1029,5 & 317,7 & & \\
\hline & 1029,2 & 317,4 & & \\
\hline Média & 1031,63 & 319,83 & & \\
\hline Variância & \multicolumn{2}{|c|}{15,66} & & \\
\hline Desvio Padrão & \multicolumn{2}{|c|}{3,96} & & \\
\hline Int. Conf. (95\%) & \multicolumn{2}{|c|}{0,14} & & \\
\hline
\end{tabular}

Tabela III - Determinação da massa específica unitária do resíduo de gesso.

[Table III - Determination of specific mass unit of the waste gypsum.]

\begin{tabular}{lccc}
\hline & $\begin{array}{c}\text { Frasco }+ \\
\text { gesso } \\
(\mathrm{g})\end{array}$ & $\begin{array}{c}\text { Frasco }+ \text { gesso } \\
+ \text { água } \\
(\mathrm{g})\end{array}$ & $\begin{array}{c}\text { Massa } \\
\text { unitária } \\
\left(\mathrm{g} / \mathrm{cm}^{3}\right)\end{array}$ \\
\hline & 124,1 & 349,0 & 2,36 \\
& 109,9 & 341,6 & 2,48 \\
Média & 108,4 & 340,9 & 2,51 \\
Variância & 114,1 & 343,8 & 2,45 \\
Desvio Padrão & 75,1 & 20,1 & 0,01 \\
Int. Confiança (95\%) & 8,7 & 4,5 & 0,08 \\
\hline
\end{tabular}

\section{Características da telha}

Massa: a partir do modelo 3D desenvolvido, é possível retirar os valores de volume dos materiais da telha, e com os valores da massa específica aparente encontrados é possível determinar a quantidade em massa das matérias primas componentes da telha. O volume a ser inserido de gesso é de $2.590,36 \mathrm{~cm}^{3}$, multiplicado pelo valor encontrado de massa específica aparente determinada, de $0,802 \mathrm{~g} / \mathrm{cm}^{3}$, serão necessários 2.077,47 g de resíduo de gesso moído para ser inserido em cada telha. No caso do PET, considerando a densidade do material de $1,38 \mathrm{~g} / \mathrm{cm}^{3}$ medida por Röchling [21], e o volume medido em CAD de $1.024,11 \mathrm{~cm}^{3}$, tem-se que cada telha possui $1.413,27 \mathrm{~g}$ de PET. Somando-se os dois valores, encontrou-se a massa total da telha que é de $3.490,74 \mathrm{~g}$, aproximadamente $3,5 \mathrm{~kg}$ por telha.

Fonte da matéria prima: a principal fonte de resíduos de gesso é a construção civil, porém como não existe ainda a conscientização para a separação e destinação adequada do resíduo [22], não se sabe ao certo a sua quantidade disponível para reutilização de uma grande cidade, como por exemplo, Curitiba. Ao contrário do gesso, o resíduo de PET é coletado e reciclado em grande escala, então é possível comprar de companhias de coleta de resíduo. É necessário que para a produção de telhas transparentes, que apenas o resíduo transparente seja utilizado, e ele deve ser também lavado e picotado para então ser transformado.

Produção: no que concerne à produção, primeiramente é feita a parte plástica que envolve a telha. Os resíduos de PET moído são misturados com grânulos de PET virgem em uma proporção de 50\% em massa de cada. Esta mistura com o elemento virgem é necessária para manter a transparência que é desejável para a telha, resultando também um produto final com propriedades intermediárias dos dois materiais [23]. Caso o processo de fabricação produza muitas sobras, é possível que a mistura seja de 33,3\% iguais em massa de resíduo de PET, PET virgem e sucata da produção. Após os grânulos serem misturados, passam por um processo de secagem que pode durar até $10 \mathrm{~h}$. A homogeneização dos materiais fica dificultada [23], pois o grânulo do material virgem e a garrafa moída apresentam massas específicas diferentes $\left(1,378 \mathrm{~g} / \mathrm{cm}^{3}\right.$ e $1,345 \mathrm{~g} / \mathrm{cm}^{3}$, respectivamente). Por isso é necessário que o material seja extrudado e picotado novamente para obter grânulos com densidade maior que o moído. Para evitar a degradação pela radiação solar, são adicionados juntamente com o resíduo aditivos que protegem contra a ação dos raios UV [16]. É feita então a injeção do plástico no molde próprio para a telha colonial gigante, tendo espessura de paredes de $2 \mathrm{~mm}$, e um vazio interno de $11 \mathrm{~mm}$ para a inserção do resíduo de gesso, conforme as figuras apresentadas do modelo. Na extremidade maior da telha são deixados um buraco e uma rebarda para no final do processo a telha ser selada. O resíduo de gesso deve ser preparado antes de ser inserido na telha. Primeiramente ele deve ser separado, e os materiais impróprios devem ser retirados. O gesso também deverá ser seco e então moído para que seus grãos sejam passantes na peneira de $2,38 \mathrm{~mm}$ de abertura. O material seco facilita tanto sua moagem e peneiramento como também auxilia para que não fique nenhuma umidade dentro da telha. $\mathrm{O}$ pó do resíduo é então despejado no interior da telha plástica, não necessitando fazer nenhuma compactação. Após a inserção do pó do gesso, a telha é selada termicamente por processo de fusão, evitando que haja infiltração por emendas. A rebarba que sobra da selagem é removida, e poderá ser reincorporada no processo.

Instalação do telhado: uma informação importante para a instalação e comercialização da telha é saber a quantidade 
de telhas necessárias para a ocupação de um metro quadrado em área do telhado. Esta característica foi determinada junto com o modelo 3D da telha GePET ao desenhar um metro quadrado, resultando em uma quantidade aproximada para ocupar esta metragem. Pode-se considerar a quantidade necessária para execução de um metro quadrado de telhado de aproximadamente 10 telhas coloniais gigantes. Outro importante fator é a inclinação mínima que o telhado deve apresentar. Esse fator é determinado dependendo do modelo da telha, e varia de acordo com o comprimento também. Uma inclinação menor que a mínima dificulta o escoamento da água na telha, gerando muitas vezes acúmulos de água indesejáveis às telhas. Outro importante fator para a montagem do telhado é a galga média. A NBR 15310/2009 a define como "atributo da relação entre as telhas", e sua determinação em ensaio é normatizada no Anexo E da mesma norma. Na prática a galga pode ser considerada como a distância entre as faces superiores de dois sarrafos. Neste caso, a galga média foi definida teoricamente por meio do encaixe das peças. $\mathrm{O}$ afastamento mínimo conforme o encaixe é de $52,4 \mathrm{~cm}$, e o afastamento máximo é de $54,4 \mathrm{~cm}$, sendo a média dos dois números a galga média de valor $53,4 \mathrm{~cm}$.

Para a montagem da telha após o ripamento pronto, é necessário que seja feita duas fileiras por vez de cima para baixo, sempre acompanhado de uma verificação com a régua metálica para manter o alinhamento. As telhas canais devem também estar separadas entre si por três centímetros, e o lado de maior diâmetro está voltado para cima, no caso da capa, este fica voltado para baixo.

Para a amarração das telhas, foram pré-dimensionados no modelo orifícios nas peças de encaixe da parte superior e inferior pelas quais poderão ser passados arames que serão amarrados nas ripas de madeira. Em localidades onde há maior ocorrência de ventos fortes, como zonas costeiras, existe maior necessidade de fazer a amarração. Como não será possível fazer furos na telha, para que o resíduo de gesso não saia e não haja infiltração da água, foi pensado este sistema de amarração discreto que não prejudicará a estanqueidade do telhando, gerando pontos onde poderia haver infiltração.

Manutenção e durabilidade: a telha GePET, por ter uma camada protetora de PET apresenta diversas vantagens em relação à manutenção e durabilidade. O PET tem baixa porosidade [16] não acumulando mofo e umidade na telha, não necessitando de limpeza tão frequente como as telhas cerâmicas, podendo ser limpa simplesmente com água e sabão. Para ser feita a manutenção de telhado, poderá haver movimentação sobre o mesmo apenas levando em consideração que deverá ser pisado sobre o ripamento, onde é a estrutura do telhado. Apesar do PET apresentar grande durabilidade, não se sabe ao certo quanto tempo durará a telha exposta ao sol, sendo considerada apenas uma estimativa a partir de telhas de resíduo de PET existentes no mercado. A empresa Telhas Leve, produtora de telhas com resíduo de PET afirma que a expectativa de vida da sua telha é de 40 anos, sendo que o PET virgem em meio às intempéries leva aproximadamente 300 anos para se degradar. Na telha GePET, a inserção do gesso não deve alterar a durabilidade do produto pois ele se encontra em estado inerte, não reagindo com o PET. Assim, espera-se que a telha apresente vida útil de aproximadamente 40 anos.

Descarte após sua vida útil: após o fim da vida útil e a troca do telhado, as telhas poderão ser destinadas para as Áreas de Transbordo e Triagem, ou então ser encaminhada diretamente para a empresa produtora. As telhas poderão ser "abertas" para a retirada do pó de gesso de seu interior. Tendo-se as duas matérias-primas separadas, é possível destiná-las tanto para a reciclagem como para aterros. O PET perde algumas propriedades importantes no quinto ciclo de reciclagem [23]. Porém, no estudo não foi incorporado PET virgem no processo, o que pode acarretar em mais ciclos de reciclagem por conta da mistura. Já o gesso poderá ser reutilizado tanto na continuidade da fabricação da telha, como também poderá ainda ser transformado em fertilizante para a agricultura, ou ter outra finalidade apropriada.

Albedo: como a telha GePET apresenta uma cobertura plástica, acumulará menos resíduos, pois apresenta menos poros. Mantendo a transparência do PET, e consequentemente a cor branca da telha por mais tempo, possibilita ainda fácil lavagem e qualquer sujeira que possa atrapalhar esta propriedade poderá ser removida com facilidade. Dentre os benefícios dos telhados brancos podem-se citar os mais relevantes para o caso: diminuição das ilhas de calor, diminuição da emissão de gases do efeito estufa, redução do custo associado a sistemas de condicionamento de ar em até $20 \%$, entre outros [24].

Isolamento térmico: outra vantagem associada ao albedo para a diminuição do calor interno das edificações ao usar a telha GePET, é o isolamento térmico que ela proporcionará. Isto porque os dois componentes da telha, juntamente com o ar incorporado nos vazios do gesso, são isolantes térmicos. Assim, não transmitem calor com facilidade e possuem baixo índice de condutividade térmica: $0,22 \mathrm{~W} / \mathrm{mK}$ e $0,026 \mathrm{~W} / \mathrm{mK}$ para o gesso e o ar, respectivamente [25] e $0,24 \mathrm{~W} / \mathrm{mK}$ para o PET [26].

Valor da telha: o valor da telha GePET foi estimado mediante comparações com produtos similares. Primeiro considerou-se o valor para a produção da parte plástica, a estimativa foi feita através da comparação em massa com outra telha colonial de PET. A telha colonial vendida pela empresa Representações RS (2014) tem 270 g em massa, seu preço é de $\mathrm{R} \$ 12,90$ por peça e são necessárias 27 peças para cobertura de $1 \mathrm{~m}^{2}$. Feita uma proporção em massa, sendo que a telha GePET tem $1.413,27 \mathrm{~g}$ por telha, o preço da parte plástica seria de $\mathrm{R} \$ 67,52$, sendo considerado já o valor da matéria prima do plástico, a produção, a distribuição do produto e todos os custos envolvidos comercialmente. Com relação ao resíduo de gesso considerou-se apenas o custo da moagem, peneiramento e enchimento das telhas. Assim, estimou-se o custo de $\mathrm{R} \$ 2,00 / \mathrm{kg}$ de resíduo de gesso. Como são inseridos $2.077,57 \mathrm{~g}$ em cada telha, o custo do gesso na telha seria de $\mathrm{R} \$ 4,15$. Assim, o preço final de venda da telha seria de aproximadamente $\mathrm{R} \$ 72,00$. Fazendo um comparativo com a telha de PET colonial comercializada, 
seu custo por metro quadrado é de R $\$ 361,2$ e sua carga por $\mathrm{m}^{2}$ é de $7,56 \mathrm{~kg}$ enquanto o custo por metro quadrado da telha GePET é de R $\$ 720,00$ e a carga por $\mathrm{m}^{2}$ é $35 \mathrm{~kg}$. Neste caso, além de a telha GePET ser quase duas vezes mais cara, a estrutura também deverá ser mais robusta, gerando um custo total mais elevado. Comparando com a telha colonial gigante cerâmica, seu preço segundo Colonial Telhas e Tijolos é em média $\mathrm{R} \$ 36,00 / \mathrm{m}^{2}$. Sendo considerado 9 peças por $\mathrm{m}^{2}$ conforme a fabricante, o preço de cada peça é de $\mathrm{R} \$ 4,00$. Sua carga por $\mathrm{m}^{2}$ é de $72 \mathrm{~kg}$. Como a telha estudada custa $\mathrm{R} \$ 720,00 / \mathrm{m}^{2}$ e apresenta a massa de $35 \mathrm{~kg} / \mathrm{m}^{2}$, verificase que o valor do modelo é muito maior que o convencional, sendo que a telha cerâmica representa apenas $5 \%$ do valor da telha GePET por metro quadrado. Esta diferença é reduzida ao se considerar que a telha cerâmica pesará aproximadamente o dobro e necessitará de uma estrutura mais robusta que a telha de GePET, porém este valor não é tão significativo a ponto de poderem ser equalizados seus custos totais.

\section{Vantagens}

Um dos pontos importantes da telha GePET é o grande apelo ambiental que ela tem, levando em consideração que é produzida unicamente com resíduos, é também reciclável, sendo que tanto o PET como o gesso incorporado poderão ser reutilizados depois separadamente. Também se pode considerar a atratividade do albedo que a telha possui, pois auxilia no conforto térmico dentro da edificação, tanto pelo albedo como pelos materiais isolantes que a compõem. Outra vantagem decorrente do uso da telha é que sua durabilidade e manutenção são facilitadas, pois o PET possui menos poros e acumulará menos detritos e umidade, sendo que desta forma sua limpeza também será facilitada. Deve ser considerada também a alta durabilidade da telha devido à grande vida útil do PET. Com relação às características físicas da telha GePET, esta possui grandes dimensões, sendo que desta forma sua montagem é simplificada. A telha também é mais leve que a telha similar cerâmica, facilitando também a montagem, o transporte e a execução de uma estrutura do telhado mais simples do que se fosse utilizada a telha cerâmica. A telha GePET apresentada também possui formas mais regulares que o modelo cerâmico, pois seu processo produtivo por injeção confere maior precisão de produção.

\section{Desvantagens}

Um dos grandes pontos negativos encontrados foi $\mathrm{o}$ preço estimado da telha, que se apresentou muito acima do mercado, incluindo as próprias telhas de PET já produzidas. Desta forma, a única maneira viável de comercialização seria a destinação do produto aos empreendimentos de alto padrão, sendo vendida como um diferencial para o mercado. Outra dificuldade é que apesar de ser obrigatória a separação e destinação do resíduo de gesso, isto não costuma ser feito de forma correta, já que o gesso muitas vezes é misturado com o entulho, ou é descartado nos aterros sanitários. Desta forma ainda há dificuldade da obtenção do resíduo de gesso não misturado com outros entulhos. Outra desvantagem é que o processo produtivo da telha de PET com gesso é mais sofisticado que a produção de outras telhas, como a cerâmica ou a de concreto, por exemplo. Assim, será necessário maior investimento em maquinário para a sua produção e especialização da mão de obra.

\section{CONCLUSÕES}

Com este trabalho foi possível listar possibilidades de telhas compatíveis com a utilização de resíduos de gesso. Da análise de dez modelos de telhas investigaramse características favoráveis nos aspectos: ecológico, durabilidade, peso, método construtivo, rendimento, mercado, manutenção e descarte, e das incertezas de mercado. Dos resultados da análise escolheu-se o tipo de telha mais adequado para detalhamento do modelo. $\mathrm{O}$ tipo escolhido foi telha colonial gigante, com cobertura de PET e inserção do resíduo de gesso em pó. O modelo foi batizado de GePET, por conta da utilização dos resíduos de gesso e PET. Foram analisadas em laboratório algumas propriedades físicas do resíduo de gesso coletado em obra, e foi encontrada umidade de $14,5 \%$ em massa e $0,802 \mathrm{~g} /$ $\mathrm{cm}^{3}$ de massa específica aparente e $2,45 \mathrm{~g} / \mathrm{cm}^{3}$ de massa específica unitária. Foi possível desenvolver um modelo 3D no programa Autocad da Autodesk, com as dimensões da telha GePET, e a partir das características geométricas e propriedades dos materiais concluiu-se que a telha possuirá massa de aproximadamente $3,5 \mathrm{~kg}$. Foi possível determinar também que serão necessárias 10 peças para compor um metro quadrado de telhado, e que a galga média da telha é de 53,4 cm. Dentre as características encontradas da telha GePET, pode-se concluir que existem as seguintes vantagens: apelo ecológico por ser reciclável e suas matérias-primas resíduos; traz conforto térmico por sua cor branca e pelas propriedades dos materiais, diminuindo também o consumo de energia; maior durabilidade; manutenção facilitada; facilidade de instalação; menor massa que a telha cerâmica equivalente; formas mais regulares, entre outros. Uma desvantagem encontrada foi o custo calculado, de $\mathrm{R} \$ 720,00$ por metro quadrado, sendo que o valor da telha cerâmica de forma equivalente representa apenas $5 \%$ do valor da telha GePET por metro quadrado. Conclui-se que a produção de telha GePET é tecnicamente viável e este possui diversas vantagens comerciais e ambientais, porém poderá ser inviável comercialmente por conta do seu custo elevado. Sugere-se para a realização em futuros trabalhos a avaliação da diminuição do preço da comercialização de telhas de resíduo de gesso, verificando se há ou não viabilidade da comercialização da telha GePET. Outra sugestão é estudar a incorporação do gesso à matriz do resíduo de PET, uma vez que telhas dessa forma já são comercializadas. Pode-se também produzir massa de resina acrílica com gesso, sendo estas prensadas e moldadas em formas investigando-se resistência e umidade, por exemplo. 


\section{REFERÊNCIAS}

[1] M. A. Cincotto, V. M. John, "Gesso de construção civil", in: G. C. Isaia, Materiais de construção civil, Ibracon, S. Paulo, SP (2007) 727.

[2] E. G. R. Petrucci, Materiais de Construção, 11ª Ed., Globo, S. Paulo, SP (1998) 438.

[3] P. H. L. Ambrozewicz, Materiais de Construção, Pini, S. Paulo, SP (2012) 460.

[4] C. T. Formoso, "Abatiendo costos mediante la disminución de pérdidas y desperdícios", in: Anais Primer Foro Internacional sobre Gestión Empresarial em La Construción (1999) 8.

[5] V. Agopyan, U. E. L. de Souza, J. C. Paliari, A. C. de Andrade, "Alternativas para redução do desperdício de materiais nos canteiros de obra", Coletânea Habitare, 2, cap.10, Inovação, Gestão da Qualidade \& Produtividade $e$ Disseminação do Conhecimento na Construção Habitacional, Antac, Porto Alegre, RS (2003) 488.

[6] S. Leusin, "Existe inovação nas edificações?", Enc. Nac. Eng. Prod., Unimep/Abepro, Piracicaba, SP, 16 (1996) 12.

[7] G. de. Aguiar, "Estudo de argamassas com agregados reciclados contaminados por gesso de construção", Diss. Mestrado Construção Civil, Esc. Polit. Universidade de S. Paulo, S. Paulo, SP (2004) 310.

[8] F. C. S. Marcondes, "Sistemas logísticos reversos na indústria da construção civil: estudo da cadeia produtiva das chapas de gesso acartonado", Diss. Mestrado, Eng. Constr. Civil Urb., Esc. Polit. Universidade de S. Paulo, S. Paulo, SP (2007) 365 p.

[9] Conselho Nacional Meio Ambiente, "O que é o CONAMA?", disponível em < http://www.mma.gov.br/ port/conama/estr.cfm $>$ (2013).

[10] Conselho Nacional Meio Ambiente, Resol. 307/2002, Alt. Resol. 348/2004, 431/2011, 448/2012, disponível em $\quad<$ http://www.mma.gov.br/port/conama/legiabre. cfm?codlegi=307>, acesso em 25/08/2013.

[11] S. M. de M. Pinheiro, "Gesso reciclado: avaliação de propriedades para uso em componentes", Tese Dr., Fac. Eng. Civil, Universidade Estadual de Campinas, Campinas, SP (2011) 330 .

[12] L. Peres, M. Benachour, V. A. dos. Santos, "O gesso produção e utilização na construção civil”, Bagaço, Recife (2008).
[13] M. Gueths, Entulho engessado, Rev. CREA/PR, Toda $59^{\mathrm{a}}$ Ed., Curitiba, PR (2009) 32.

[14] L. Peres, M. Benachour, V. A. dos. Santos, "O gesso produção e utilização na construção civil”, Bagaço, Recife (2001) 94.

[15] Viapol, Viaflex Branco, disponível em: $<$ http://www. viapol.com.br/produtos_desc.php?menu=quimicos\& codigo_item $=32>(2013)$.

[16] I. S. de. Almeida, I. M. D. Costa, M. M. de O. Ribeiro, M. Heinrich, Q. Moreira, P. J. P. Araujo, M. S. Leite, "Reciclagem de garrafas PET para fabricação de telhas", Cad. Grad. - Ciências Exatas e Tecnológicas, 1, 17 (2013) 83.

[17] Associação Brasileira de Normas Técnicas, NBR 15310: Componentes cerâmicos - Telhas - Terminologia, Requisitos e Métodos de Ensaio", Rio de Janeiro, RJ (2009). [18] Associação Brasileira de Normas Técnicas, NBR NM 45: "Agregados - Determinação da massa unitária e do volume de vazios", Rio de Janeiro, RJ (2006).

[19] Associação Brasileira de Normas Técnicas, NBR NM 52: "Agregado miúdo - Determinação de massa específica e massa específica aparente”, Rio de Janeiro, RJ (2009).

[20] M. A. Paoli, M. A. Spinacé, “A tecnologia da reciclagem de polímeros", Quim. Nova 28, 1 (2005) 17.

[21] Röchling, "High Performance Plastics", Sustadur PET, Product Hand. Inf. Sh. (2012) 20.

[22] A. Nagalli, "The Sustainability of Brazilian Construction and Demolition Waste Management System", Electr. J. Geotech. Eng. 18 (2013) 1755-1759.

[23] S. D. Mancini, M. N. Bezerra, M. Zanin, "Reciclagem de PET Advindo de Garrafas de Refrigerante Pós-Consumo", Polímeros 8, 2(1998) 7.

[24] J. A. das. Graças, "Residências sustentáveis e sua contribuição ao meio ambiente", Diss. Mestrado, Universidade do Minho, Escola de Engenharia, Braga, Portugal (2010) 149.

[25] Y. A. Çenger, A. J. Ghajar, Transferência de calor e Massa, uma Abordagem Prática, 4a Ed., The McGraw-Hill Co. Inc., New York, EUA (2011) 906.

[26] N. R. G. dos. Santos, "Projeto, Construção e Análise de Desempenho de Coletores Solares Alternativos Utilizando Garrafas PET", Diss. Mestrado, Eng. Mec., Universidade do Rio Grande do Norte, Natal, RN (2007) 100.

(Rec. 08/07/2014, Rev. 23/11/2014, 10/03/2015, Ac. 21/03/2015) 